\title{
A relational analysis of acute wheezing and air pollution
}

\author{
Manouri P Senanayake ${ }^{1}$, R P Samarakkody ${ }^{2}$, S P Sumanasena ${ }^{3}$, J Kudalugodaarachchi ${ }^{3}$, S R Jasinghe ${ }^{2}$, \\ A P Hettiarachchi ${ }^{4}$
}

Sri Lanka Journal of Child Health, 2001; 30: 66-8

(Key words: Hospital attendance, severe wheezing, sulfur dioxide, oxides of nitrogen, ambient air)

\begin{abstract}
Objective To correlate hospital attendance for wheezing treated with nebulizer therapy with pollutant levels recorded in ambient air in Colombo.
\end{abstract}

Setting Emergency treatment unit (ETU) of the Lady Ridgeway Hospital, Colombo.

Design A prospective observational case control study.

Method Attendance at the ETU for nebulizer therapy was recorded daily for 12 months. ETU attendance for conditions other than wheezing served as controls. The case and control attendance rates were correlated with daily maximum and minimum one hour average levels of sulfur dioxide and oxides of nitrogen in ambient air as measured by the continuous pollution monitor situated in the Fort, Colombo.

Results 30,932 children needed nebulizer therapy in the ETU (median daily attendance 85) during the period of 12 months. The control population was 10,100 children (median daily attendance 28 ). The pattern of pollutant levels and attendance rates for wheezing showed a correlation on a time series.

Conclusion Air pollution levels in Colombo correlated significantly with hospital attendance rates for wheezing needing emergency treatment. The highest recorded levels of sulfur dioxide and oxides of nitrogen in ambient air showed a significant correlation with the highest hospital attendance rates, and the lowest pollutant levels with the lowest hospital attendance rates. We conclude that vehicle related pollutants in ambient air in Colombo are affecting the respiratory health of children.

\footnotetext{
${ }^{1}$ Senior Lecturer in Paediatrics, Faculty of Medicine, Colombo, ${ }^{2}$ Scientist, Environmental Division, National Building Research Organization, Colombo, ${ }^{3}$ Medical Officer, Lady Ridgeway Hospital, Colombo, ${ }^{4}$ Project Assistant, Environmental Division, National Building Research Organisation, Colombo.
}

\section{Introduction}

Epidemiological data shows a significant increase in childhood asthma throughout the world, in the past three decades ${ }^{1,2,3,4}$. This sharp rise in incidence and prevalence of acute wheezing is believed to be environmental and not genetic in aetiology 5 . Air pollution has been documented to contribute to respiratory disease and wheezing in children and is a public health concern in many cities ${ }^{6,7,8,9,10,11}$. Automotive emissions are considered the major source of air pollution in urban areas ${ }^{11}$.

In Sri Lanka, respiratory diseases are the leading cause of hospitalisation in children and the second commonest cause at all ages ${ }^{12}$. The numbers of children needing bronchodilator therapy at the Lady Ridgeway Hospital, Colombo is increasing each year. There has been a steep incline in the vehicle population in Sri Lanka over the last 25 years. The traffic in Colombo grows by $5 \%$ each year and it is estimated that $50 \%$ or more of the total vehicle fleet of Sri Lanka plies in the Colombo metropolitan area ${ }^{13}$. The exposure of the city dwelling child to automotive air pollution needs attention. We investigated for an association between hospital attendance for episodes of severe wheezing and air pollutant levels in the city.

\section{Method}

All children under the age of 12 years presenting to the emergency treatment unit (ETU) of the out patient department (OPD) of the Lady Ridgeway Hospital (LRH) Colombo with acute wheezing needing nebulizer therapy with bronchodilators were included in the study during a period of one year (1 July '98 to 30 June '99). Their attendance was recorded on a daily basis. Patients attending the ETU with conditions other than wheezing served as controls.

Air pollution data were measured in the Continuous Air Quality Monitoring Station operated by the Environmental Division of the National Building Research Organization (NBRO), Central Environmental Authority of Sri Lanka. This station is situated in the Colombo Fort, $3 \mathrm{~km}$ from the Lady Ridgeway Hospital. 
The daily maximum and minimum one-hour averages of sulfur dioxide and oxides of nitrogen were correlated with daily case and control attendance rates. The statistical package "Statistica" was used to analyse data on a weekly (Sunday to Saturday) basis over a period of 51 weeks.

\section{Results}

30,932 children attended the out patient department with wheezing needing urgent nebulization (median daily attendance 85) from 1 July 1998 to 30 June 1999. 10,100 children attended for conditions other than wheezing during these 12 months.
During the period of study the daily one hour averages of ambient sulfur dioxide and oxides of nitrogen varied from $0.1 \mathrm{ppm}$ to $0.01 \mathrm{ppm}$ and from $0.28 \mathrm{ppm}$ to $0.04 \mathrm{ppm}$ respectively.

It was observed that the changing pattern of both pollutants were consistent $(\mathrm{r}>0.6)$. All the measured parameters (daily case and control attendance rates, daily maximum one hour concentrations of sulfur dioxide and oxides of nitrogen) were normally distributed throughout the period of study. Due to technical and calibration problems data was not valid for analysis in all 51 weeks. The number of valid weeks are shown in Table 1.

\section{Table 1}

Association of pollutant levels and hospital attendance rates

Pollutant Concomitant occurrence in weeks (number of weeks studied) Maximum Pollution and Maximum Attendance Minimum Pollution and Minimum Attendance

$\begin{array}{ccccc} & \text { Severe Wheezing } & \text { Control } & \text { Severe wheezing } & \text { Control } \\ \mathrm{SO}_{2} & 16(41) & 08(37) & 22(48) & 14(44) \\ \mathrm{NO}_{x} & 13(47) & 07(43) & 27(49) & 20(49)\end{array}$

There was a concomitant occurrence of the highest number of episodes of nebulisation on the most polluted day (with respect to sulfur dioxide and oxides of nitrogen) and the lowest number of nebulisations on the least polluted day in a given week, in a statistically significant number of weeks throughout the year (binomial test, $\mathrm{p}=0.05$ ).

\section{Discussion}

There is mounting evidence from studies carried out abroad that the increase in prevalence of asthma may be due to vehicle-related pollutants. A significant association between wheezing and traffic exposure has been reported among children in Europe, U.S.A., and U.K. Our paper is based on a similar study carried out in a hospital in Middlesex, London $^{14}$.

The LRH accepts sick children from any area of residence free of charge and is the only children's hospital in the city. Its outdoor and indoor caseload far outnumbers children treated in any other hospital in the city. Therefore data from the ETU of the OPD of LRH can be considered to reflect the prevalence of severe wheezing in the community as a whole. The attendance rate at the OPD of this hospital is an unbiased sample because the majority are self-referrals.
The ETU caters to patients needing urgent attention. Clinical distinction between bronchiolitis, wheezy bronchitis and atopic asthma is sometimes not possible at a young age and was not attempted since the accuracy of diagnosis is not an issue in this study. All patients with wheezing (i.e. bronchospasm) were considered as a whole.

Epidemiological studies which have linked air pollutants and asthma have failed to establish an increased risk of asthma in persons living close to busy roads ${ }^{15}$. Therefore we did not analyse the place of residence because the home environment is a poor indicator of personal exposure to traffic related pollutants and may represent only a small fraction of exposure to outdoor air which occurs at school, in playgrounds, and during commuting.

Air pollutants such as suspended particulate matter, oxides of nitrogen, sulfur dioxide, ground level ozone and combination of these are known to increase the risk of respiratory diseases. We investigated only ambient sulfur dioxide and oxides of nitrogen, which represent emissions from both diesel and petrol combustion.

The high significance in correlaton between daily rates of nebulization and pollutant levels in ambient air which we found, indicates an association between air pollution and severe wheezy episodes in children in Colombo. We conclude that the 
ambient air in Colombo has reached a level of pollution at which it either initiates or exacerbates wheezing in children requiring nebuliser therapy and thereby affects attendance rates at hospitals.

\section{Acknowledgement}

We thank the Director, Lady Ridgeway Hospital for granting permission for this study and the nursing staff of the Emergency Treatment Unit for their invaluable help.

\section{References}

1. Helms P J, Christie G. Prospects for Preventing Asthma. Archives of Disease in Childhood 1999; 80:401-3.

2. Burr M L, Rutland B K, King S, VaughnWilliams E, Changes in asthma prevalence: two surveys 15 years apart. Archives of Disease in Childhood 1989; 64:1452-6.

3. Robertson C F, Heycock E, Bishop J, Nolan T, Olinsky A, Phelan P D. Prevalence of asthma in Melbourne school children: changes over 26 years: British Medical Journal 1991; 302:1116-8.

4. Ninan T K, Russel G. Respiratory symptoms and atopy in Aberdeen school children: evidence from two surveys 25 years apart. British Medical Journal 1992; 304: 873-5.

5. Bronchial asthma, Weekly Epidemiological Report - Ministry of Health, December 1998,(26), 52.

6. Wjst M, Reitmeir M, Dold S, Wuff A, Nicolai T, Freifrau von Loeffelholz Colberg E, et al.; Road traffic and adverse effects on respiratory health in children, British Medical Journal 1993; 307: 596-600.
7. Weiland S K, Nundt K A, Ruckman A, Keil U. Self reported wheezing and allergic rhinitis in children and traffic density on street of residence. Annals of Epidemiology 1994; 49: 223-7.

8. Waldron G, Pottle B, Dod J. Asthma and the motorways -one district's experience. Journal of Public Health Medicine 1995; 17:85-9.

9. Nitta H, Sato T, Nakai S, Maeda K, Aaoko S, Ono M. Respiratory health associated with exposure to automobile exhaust. Results of crosssectional studies in 1979, 1982 and 1983. Archives of Environmental Health 1993; 48: 538.

10. Strachan D P. Traffic exposure and asthma: problems of interpretation, British Medical Journal 1996; 312: 677.

11. Lewis $\mathrm{P} \quad \mathrm{R}$, Hensley $\mathrm{M} \mathrm{J}$, Wlodarozyk $\mathrm{J}$, Toneguzzi R C, Westley-Wise V J, Dunn T, Calvert D. Outdoor air pollution and children's respiratory symptoms in the steel cities of New South Wales. Medical Journal of Australia 1998; 169: 459-63.

12. Annual Health Bulletin Ministry of Health Colombo 1997:22.

13. Samarakkody $R \quad P$, Yalegama $M S S$ B, Aluthwala P N. Some aspects of air pollution in Colombo City. Proceedings of the Commonwealth Science Council workshop on Acid Rain monitoring and atmospheric modeling. University of Peradeniya, Sri Lanka 1998: 20-26.

14. BuchdahI R, Parker A, Stebbings T, Babker A. Association between air pollution and acute childhood wheezy episodes: prospective observational study. British Medical Journal 1996; 312: 661-5.

15. Livingstone A E, Shaddick G, Grundy C, Elliott $P$. Do people living near inner city main roads have more asthma needing treatment? Casecontrol study. British Medical Journal 1996; 312:676. 